\title{
Digital Factory Assistant: Conceptual Framework and Research Propositions
}

\author{
Mohamed Anis Dhuieb, Florent Laroche, and Alain Bernard \\ LUNAM Université, Ecole Centrale de Nantes, IRCCyN UMR CNRS 6597, France \\ Mohamed-anis.dhuieb@irccyn.ec-nantes.fr
}

\begin{abstract}
Nowadays, knowledge has a major role in factory efficiency. The integration of knowledge and decision support systems in the whole factory process appears as a key for the factory of the future. The basic concept of our research work is facilitating interactions between the human being in critical working situations and information set in the factory. Our proposition is to develop a "digital factory assistant" to provide factory actors with the right information, in the right time and place. Our purpose is to build a generic factory model based on context awareness and decision support models and then create relevant information and knowledge extraction mechanisms. In this paper we discuss the conceptual architecture of the desired information system.
\end{abstract}

Keywords: Knowledge Management, PLM, Virtual Assistant, Ubiquitous computing.

\section{Introduction}

Industrials and researches illustrate different visions of the factory of the future. The shared aspect of these visions is providing the factory's employers with consistent IT systems to simplify and support employee's tasks.

Based on an integrated approach of material-processes-information-human being, our proposition is to develop a customable company assistant that interact with complete information set. The assistant will be inspired by knowledge based systems, contain different decision aided functionalities, and use Virtual engineering technologies techniques. This will allow extending the dimensions of Virtual Technologies models with further data sets. This assistant will assist factory's actors during engineering phases by providing them with the right information. It consists of a knowledge based system which allows the access of different knowledge resources in the factory such as Product Lifecycle management (PLM) CAx models (Computer aided Design/ Manufacturing/engineering CAD/CAE/CAM...), material flows, process chains, simulation data... [1] One of the challenges in our proposition is to select the right information from numerous sources and transforms it into useful knowledge.

The first part of the paper presents a state of the art of the evolution in digital tools in the factory. The second part deals with the human being role in the product 
lifecycle as a decision maker. Some related works are presented in the third part and the fundamentals of ARTUR project, which illustrate our vision of the factory of the future, will be explained in the third part before the conclusion.

\section{Evolution of Digital Tools in Factory: Future Information Systems in Factory}

Nowadays, enterprises have acquired various tools that allow them to be very confident with the products they develop. The concept of smart factories proposes them to automate and control most of their tasks [1]. Today's factory contains more and more digital tools based on ICT. The digital and virtual factory paradigm can support the design and management of a production environment by addressing various key issues like: reduction of production times and material waste thanks to the analysis of virtual mock-ups, development of a knowledge repository where people can find stored information in different versions, with both advisory role and support to the generation of new knowledge and improvement of workers efficiency and safety through training and learning on virtual production systems [2][3].

Advanced technologies such as ubiquitous computing (i), virtual engineering technologies (ii), and the concept of the Web 3.0 (iii) are supplying the factory with a new wave of intelligence:

i) Ubiquitous Computing was first introduced by Weiser in the end of 80s. It consists of a new model of interaction where the information processing is integrated in our daily life. The context-awareness is the particular aspect of ubiquitous information systems. These information systems have to anticipate the user's needs in a particular situation and act proactively to provide appropriate assistance. Many researchers describe the vision of the factory of things which adopt the basic concepts of the internet of things and implement smart objects that interact basically on semantic services integrating knowledge representations. The main goal of such propositions is to make the information available anywhere, anytime for any user based on Weiser vision of ubiquitous computing. $[4][5][6][7][8][9]$

ii) Virtual engineering technologies become an emerging field in industry and research. Many industrials use Virtual and Augmented Reality to make advanced simulation of their manufacturing process or for training their employees. The application fields of virtual engineering can be considered for the complete life-cycle of the product, from the earliest design stages of the products to their manufacturing, assembly, use and maintenance phases. This evolution in the field of virtual engineering reflects a real modification of our way of thinking product development. Thus, global coherency has emerged as a result of improved numerical integration and better software functionality for manufacturing preparation as well as for process simulation and part dimensional and geometrical control after manufacturing. [10][11][12][13] 
iii) The Web 3.0 is the more recent technology from those mentioned previously. Mills Davis describe his vision of the web 3.0 in his industry roadmap to web 3.0: In order to connect systems, integrate information, and make processes interoperable, the first step is to integrate the knowledge about these systems, content sources, and process flows. Semantically modeled machine executable knowledge lets us connect information about people, events, locations, times, across different content sources and application processes. In Web 3.0, knowledge lives, evolves and is stored transparently. It can be used, validated, added to, and combined with other knowledge at run time by multiple systems. This enables a system to "learn" to do things that the system designer did not anticipate. This is an important shift from IT as it has been practiced until now.

The basic shift occurring in Web 3.0 is from information-centric to knowledge-centric patterns of computing. Web 3.0 encompasses a broad range of knowledge representation and reasoning capabilities including pattern detection, deep linguistics, and ontology [14] [15] [16].

In modern product development, as the complexity and variety of products increase to satisfy increasingly sophisticated customers, so does the need for knowledge and expertise for developing products. Today's knowledge-intensive product development environment requires a computational framework which effectively enables capture, representation, retrieval and reuse of product knowledge. [17][18]The factory of the future requires holistic production systems with a learning capability, based on learning effects in all stages of the process chains involved, the goal is to achieve higher production outputs by integrating knowledge modules into the engineering systems concerned [19].

As we mentioned in the introduction our proposition is to develop a customizable knowledge book called "Digital Factory Assistant". The crucial point of success of our work will be the building of a comprehensive model that represents most of the elements in the factory, seen as knowledge resources, and to guarantee the interoperability between them, but at first let's see what are the reasons that led us propose it.

\section{The Human Factor in Production Systems}

For an enterprise's management point of view, enterprise's managers make a significant effort to reduce the cost of non-quality (CONQ). Measuring and reporting this cost is a critical issue for any manager who aims to achieve competitiveness in today's markets [20]. Studies show that the lack of information, gaps in training, and the unavailability of documentation in production lines are the most important reasons of CONQ rising [21].

Despite the evolution of digital tools in factory as seen in the previous section, the role of the human being in product lifecycle is not insignificant. Labrousse [22] highlight the role of the human being as a decisional actor in the factory life. He makes the relation between information, knowledge, and decision: information is not 
easy to understand by the user, the meaning of the information can be strongly influenced by the user and the context. The knowledge is the emergence of the user and the interpreted information. In many cases elements impacting decisions are not totally mastered and suffer from incompleteness. In the process of decision making, users combine different types of data and knowledge (both tacit and explicit knowledge) available in different forms. The decision making process results in improved understanding of the problem and the process [23].

One of the solutions to reduce the cost of non-quality is developing assistant tools that help factory employees in their tasks. There are several works related to human assistance in different phases of product lifecycle. Projects deal with assistance in production phase is not very common unlike in other product lifecycle phases like design or maintenance. The next section describes few works related to the human being assistance in the factory.

\section{Previous Works Relied on Human Being Assistance in Factories}

Many propositions have been encountered in the literature. Despite the diversity of these projects, few of them deal with human assistance in production systems at a "machine level" where information is less available comparing to other departments in the factory. In this section, we discuss a number of works related on our work.

In a maintenance context, CARMMI model [24] provide support to operators during maintenance tasks through mixed reality providing information access from different sources. This model allows the acquisition and presentation of different data: CAx data, maintenance, and virtual data. From a decision making point of view, the big quantity of the information presented in the interface can reduce the efficiency of the operator to make the right decision. In fact, the interface contains augmented reality, visualization system, information and historical information data. The human machine interactions are not studied in this project.

A second work in the same context was presented by Toro [25]. A framework and a system implementation were developed for the exploitation of embedded knowledge in the domain of industrial maintenance. This framework uses a shared ontology designed to model and support pervasive computing applications called SOUPA. A knowledge acquisition system is also developed in this project called Experience Knowledge Structure. This system extends the functionality of SOUPA in a way that formal decision events can be suggested to the user during his work. Both of these two technologies were used to develop the UDKE system (User, Device, Knowledge, and Experience). This UDKE provide a conceptual model of a maintenance system that combines knowledge, user experience and Augmented Reality techniques. The context awareness notion was absent from this project so the possible decisions and information provided to the user were not relied to his task and did not consider his feedback.

Kwon [26] [27] has developed a framework called ubiDSS. ubiDSS is a framework of multi-agent and context-aware based proactive decision support system. The architecture of this framework is composed by a number of subsystems: context 
subsystem, dialogue subsystem, knowledge subsystem, model management subsystem, and a database management subsystem. Even that the application field of the ubiDSS system is far from industry, it was very important to study the interactions between the components of its framework and the models behind.

Many other propositions were encountered in the literature relied to the human being assistance in the different product lifecycle stages especially in design process. However, the application of such propositions in a production context is very rare.

\section{$5 \quad$ ARTUR: A Digital Factory Assistant}

\subsection{Concept}

Related to visions of the factory of the future, our work is to offer the factory operator with a so called "Digital Factory Assistant". Through this assistant the operator can have information from distributed knowledge resources relying in different ways of interaction in order to act upon the task that he is doing. So, the main research issue of our work is to find which information to give to the operator, where, when, and how. The basic idea is to allow each person to be able to react in given situation, mainly thanks to high speed simulation and performance evaluation models and methods. [1]

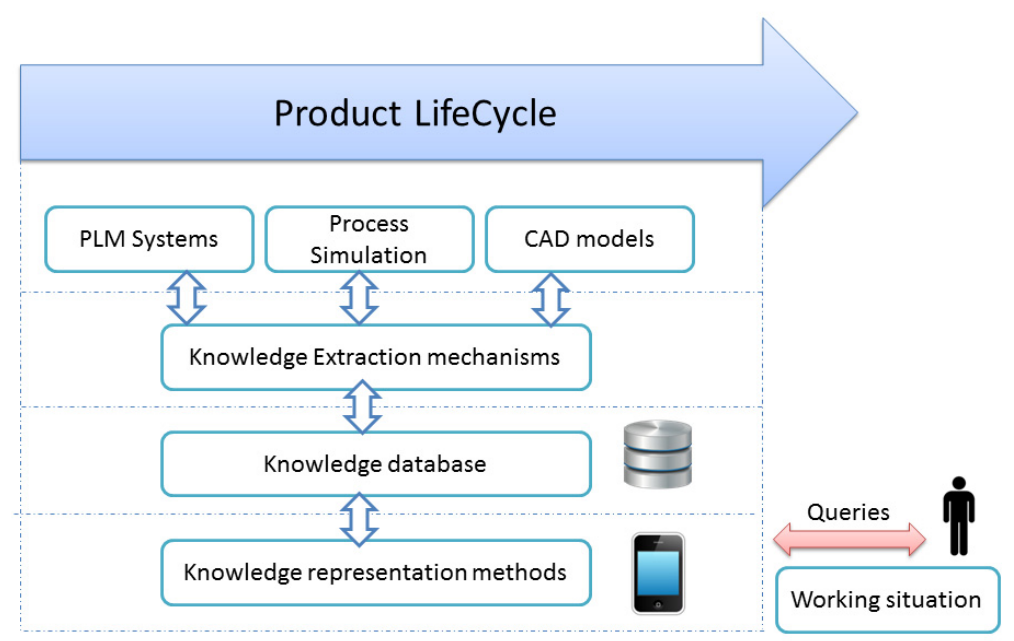

Fig. 1. Based on knowledge extraction mechanisms, knowledge will be extracted from factory information system elements compared as a lower part of an iceberg. The operator will deal only with a mobile device, compared as the top part of an iceberg, where knowledge will be deployed with intelligent navigation system [28]. 
Figure 1 outline the first proposition of the conceptual framework of our work in a high level. The framework will be based on three layers: the first one is related to the human-machine level, where contextual information related to user's working situation can be acquired. The second layer is related to the definition, representation, exploration, and structuring knowledge. The last layer deal with the issue of linking knowledge layer with the whole information system in the factory.

To build our "Digital Factory Assistant", we have to consider many points of view. In the following sections we will try to detail some of them.

\subsection{Evaluation of Human-Machine Interactions}

Interaction between the human being and the machines or environment is a topic that is often underestimated. More satisfactory relations need to take the psychological aspects into account and also improve the factory environment by controlling many factors. The relations between human beings, machines, and their environment play a central role in production systems [4].

A cognitive approach will be developed; the information quantity will be different from a beginner operator to an expert operator. With this approach, and in a context of uncertainty, the system will transfer a small amount of knowledge to a beginner user and led him, as his needs, to a larger amount of knowledge and do the opposite for a more expert user: "smooth roads never make good drivers".

\subsection{Knowledge Exploitation}

Knowledge management aims at capturing explicit and tacit knowledge of an organization in order to facilitate the access, sharing and re-use of that knowledge [29].

Foundations of our research project relate to a new proposition for modeling and structuring information, and more generally knowledge. Consequently, dealing with the global data, information, knowledge and know-how, we will be able to contextualize reusing this knowledge in any given situation that would need this knowledge [1]. Our assistant will be based on a dynamic knowledge representation: knowledge will be presented to an operator according to some relevant information including his working situation [30] [31], the maturity level [32], and the operator experience. In a process of decision making, the actor will combine different types of data and knowledge available in various forms.

The operator will have the possibility to personalize the set of information and knowledge as his need and as his evolution on the process or the service that he works on it. An intelligent knowledge and information system will be deployed in mobile device to make the information available in any context, even in complex working situations. [22][32][33]. 


\subsection{Ubiquitous Environment}

As mentioned in the first part of this paper, our system will run in an ubiquitous environment [9]. The ubiquitous environment is now emerging as a primary driver to change the decision makers' task environment. This trend certainly has the potential to improve the decision making framework in gathering and processing decision makers' contextual data in an automated way, which intelligently extracts proactive decisions [26][27]. The context-awareness is the particular aspect of ubiquitous information systems. Dey [34] has defined the context as "any information that can be used to characterize the situation of an entity. An entity is a person, place, or object that considered relevant to the interaction between the user and the application, including the user and the applications them-selves." Humans possess a different perception of contextual information, which is mostly due to the availability of context information on different levels of granularity or abstraction [35].

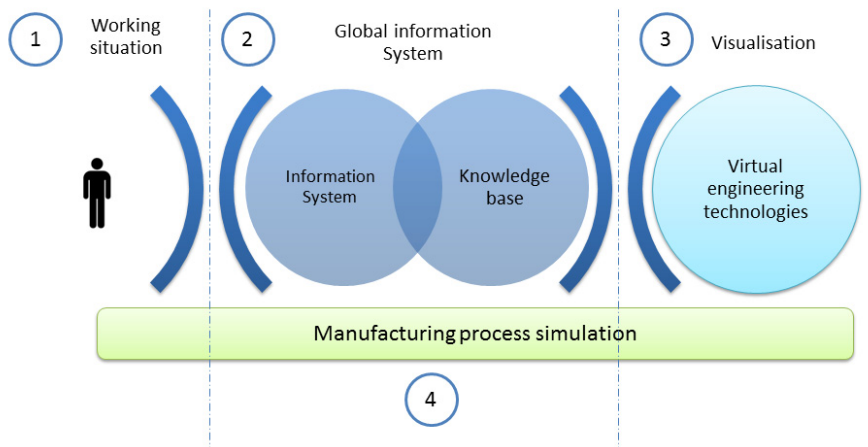

Fig. 2. Basic elements creating the ubiquitous environment

In accordance with the vision of Weiser in ubiquitous computing, our system will be based on a context aware model. The ubiquitous environment is created by the data flow coming from different resources:

- user's input dependent in his working situation (1) (this context information will act like a sensor in our model),

- the coupling of the existent information system in the factory and knowledge database (2),

- the process simulation (4) based on advanced numeric simulation technics[36],

- the extending of the virtual reality models with a further data set (3) (2).

The system will have the capability to understand the user's need by "compiling" context information and automatically "generate" the relevant information and knowledge to the user.

In addition to context awareness, reactiveness is an important requirement for a ubiquitous information environment. Proactiveness means to process information on behalf a user so an action can be taken without requiring his attention. This implies knowing what a user would want to do with the requested information, and detecting patterns for his behavior. [37] Therefore, we will define effective context information 
extraction techniques to identify the working situation of the operator and to determine the information set that will be presented.

\subsection{Future Model Aspects}

Taking into account the main aspects of our idea about the "Digital Factory assistant", our model will be based on several approaches related to enterprise, knowledge, and context modeling.

Enterprise modeling is defined by Molina [38] as the art of externalizing enterprise knowledge which adds value to the enterprise or needs to be shared. It consists of making models of the structure, behavior and organization of the enterprise. [22] A new proposition for modeling working situations will be designed. This aspect will be based on Hasan proposition [30] [31] for modeling the working situation at machine level.

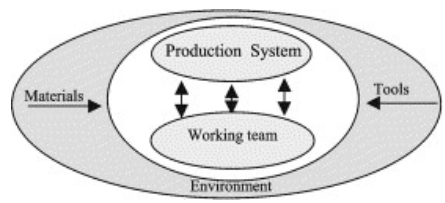

Fig. 3. Macro view of the working situation [30] [31]

A level of detail will be employed during the modeling process [13] this aspect will define the granularity of the information to be presented to the user. The desired model should be in one hand extensible to acquire more functionality and more types of data and in another hand interoperable so he can communicate and acquire knowledge and information from other existing systems in the factory.

\section{Conclusion and Future Work}

We believe that in the factory of the future the information and the knowledge will have more accessibility with small devices that interact with its user in an intelligent way. The main aspect for our vision is to extract the right information in the right time and give it to the right user. In a production system, the user may be faced with working situations that require him to interact with the machine in front of him by choosing the right decisions. The decisions can be a force to be applied, a position of a tool in the machine... So, to make his decision the user will need to have such propositions of what he can do or what measure he will take and, using advanced simulation technics, he can anticipate the influence of his choice. To validate all this aspects in our project ARTUR, we will be based on two use cases in aeronautic industry. Currently, we started a survey to identify the different elements that will help us to build our information model.

\section{References}

1. Laroche, F., Bordeu, F., Bernard, A., Chinesta, F.: Towards the factory of future An integrated approach of material-processes-information-human being. In: Proceedings of the 2012 Virtual Reality International Conference, p. 13. ACM (2012) 
2. Smith, E.A.: The role of tacit and explicit knowledge in the workplace. Journal of Knowledge Management 5(4), 311-321 (2001)

3. Terkaj, W., Pedrielli, G., Sacco, M.: Virtual factory data model. In: Proceedings of the Second International Workshop on Searching and Integrating New Web Data Sources (VLDS 2012), Istanbul, Turkey (2012)

4. Zuehlke, D.: SmartFactory Towards a factory-of-things. Annual Reviews in Control 34(1), 129-138 (2010)

5. Stephan, P.: System architecture for using location information for process optimization within a factory of things. In: Proceedings of the 3rd International Workshop on Location and the Web, p. 6. ACM (2010)

6. Guinard, D., Trifa, V., Karnouskos, S., Spiess, P., Savio, D.: Interacting with the soa-based internet of things: Discovery, query, selection, and on-demand provisioning of web services. IEEE Transactions on Services Computing 3(3), 223-235 (2010)

7. Schmidt, A.: Context-Aware Computing: Context-Awareness, Context-Aware User Interfaces, and Implicit Interaction. In: The Encyclopedia of Human-Computer Interaction, 2nd edn. (2013)

8. Kwon, O., Yoo, K., Suh, E.: UbiDSS: a proactive intelligent decision support system as an expert system deploying ubiquitous computing technologies. Expert Systems with Applications 28(1), 149-161 (2005)

9. Weiser, M.: The computer for the 21st century. Scientific American 265(3), 94-104 (1991)

10. Bernard, A., Ammar-Khodja, S., Perry, N., Laroche, F.: Virtual engineering based on knowledge integration. Virtual and Physical Prototyping 2(3), 137-154 (2007)

11. Luna, A.S., Lopez, T., Nouviale, F., Gouranton, V., Arnaldi, B.: Collaboration et interchangeabilité entre humains réels et humains virtuels en Environnement Virtuel de Formation. AFRV, 1-8 (2012)

12. Thouvenin, I.M.: Interaction et connaissance: construction d'une expérience dans le monde virtuel (Doctoral dissertation, Université de Technologie de Compiègne) (2009)

13. Laroche, F.: Contribution à la sauvegarde des Objets techniques anciens par l'Archéologie industrielle avancée. Proposition d'un Modèle d'information de référence muséologique et d'une Méthode inter-disciplinaire pour la Capitalisation des connaissances du Patrimoine technique et industriel (Doctoral dissertation, Ecole centrale de Nantes-ECN) (2007)

14. Davis, M.: Semantic Wave 2008 Report: Industry Roadmap to Web 3.0 \& Multibillion Dollar Market Opportunities. Executive Summary (2008)

15. Lai, H., Fan, Y., Xin, L., Liang, H.: The Framework of Web 3.0-Based Enterprise Knowledge Management System. In: Uden, L., Herrera, F., Bajo, J., Corchado, J.M. (eds.) 7th International Conference on KMO. AISC, vol. 172, pp. 345-351. Springer, Heidelberg (2013)

16. Hendler, J.: Web 3.0 Emerging 42(1), 111-113 (2009)

17. Ameri, F., Dutta, D.: Product lifecycle management: closing the knowledge loops. Computer-Aided Design \& Applications 2(5), 577-590 (2005)

18. Sriti, M.F.: Démarche et logiciel de gestion des connaissances pour le cycle de vie des produits. PhD report, University of troyes (2008)

19. Westkämper, E., Walter, F.: EMO Hannover 2011 showcases the factory of the future: New production concepts integrate knowledge and learn from it (2011) (press release)

20. Schiffauerova, A., Thomson, V.: Managing cost of quality: insight into industry practice. The TQM Magazine 18(5), 542-550 (2006)

21. Benhabib, A., Ghomrassi, S.: Les coûts de non-qualité. Symposium International: Qualité et Maintenance au Service de l'Entreprise QUALIMA01 - Tlemcen (2004) 
22. Labrousse, M.: Proposition d'un modèle conceptuel unifié pour la gestion dynamique des connaissances d'entreprise. PhD report, Ecole Centrale de Nantes (2004)

23. Bolloju, N., Khalifa, M., Turban, E.: Integrating knowledge management into enterprise environments for the next generation decision support. Decision Support Systems 33(2), 163-176 (2002)

24. Espíndola, D.B., Fumagalli, L., Garetti, M., Pereira, C.E., Botelho, S.S., Ventura Henriques, R.: A model-based approach for data integration to improve maintenance management by mixed reality. Computers in Industry (2013)

25. Toro, C., Sanín, C., Vaquero, J., Posada, J., Szczerbicki, E.: Knowledge based industrial maintenance using portable devices and augmented reality. In: Apolloni, B., Howlett, R.J., Jain, L. (eds.) KES 2007, Part I. LNCS (LNAI), vol. 4692, pp. 295-302. Springer, Heidelberg (2007)

26. Kwon, O., Yoo, K., Suh, E.: UbiDSS: a proactive intelligent decision support system as an expert system deploying ubiquitous computing technologies. Expert Systems with Applications 28(1), 149-161 (2005)

27. Kwon, O., Choi, S., Lee, H., Yoo, K.: UbiDSS: a framework of multi-agent based proactive decision support system with context-awareness. In: Proceedings of the Second IEEE Workshop on Software Technologies for Future Embedded and Ubiquitous Systems, pp. 172-174. IEEE (2004)

28. Carolan, S., Magnin, M., Evain, C., Moreau, G., Chinesta, F.: Developing models for enhanced learning in engineering. Innovative Pedagogy in Engineer Education (2012)

29. Sriti, M.F., Eynard, B., Boutinaud, F., Matta, N.: Towards a semantic-based plateform to imporove knowledge management in collaborative product development (2008)

30. Hasan, R., Bernard, A., Ciccotelli, J., Martin, P.: Integrating safety into the design process: elements and concepts relative to the working situation. Safety Science 41(2-3), 155-179 (2003)

31. Hasan, R., Bernard, A., Ciccotelli, J.: Proposal of a new design approach integrating the concept of the working situation. In: Gogu, G., Coutellier, D., Chedmail, P., Ray, P. (eds.) Recent Advances in Integrated Design and Manufacturing in Mechanical Engineering (2003)

32. Xu, Y.: Proposition d'un système intégrée de référence de connaissances pour l'évaluation de la connaissance dans le développement de produits. PhD Report. Ecole Centrale de Nantes (2010)

33. Ammar-Khodja, S.: Processus d'aide à la spécification et à la vérification d'application d'ingénierie à base de connaissances expertes. PhD Report. Ecole Centrale de Nantes (2007)

34. Dey, A.K.: Understanding and Using Context. Personal and Ubiquious Computing, 4-7 (2001)

35. Zimmermann, A., Lorenz, A., Oppermann, R.: An operational definition of context. In: Kokinov, B., Richardson, D.C., Roth-Berghofer, T.R., Vieu, L. (eds.) CONTEXT 2007. LNCS (LNAI), vol. 4635, pp. 558-571. Springer, Heidelberg (2007)

36. Chinesta, F., Leygue, A., Bognet, B., Ghnatios, C., Poulhaon, F., Bordeu, F., ... \& MaisonLe-Poec, S.: First steps towards an advanced simulation of composites manufacturing by automated tape placement. International Journal of Material Forming, 1-12 (2012)

37. Van Bunningen, A.H., Feng, L., Apers, P.M.: Context for ubiquitous data management. In: International Workshop on Ubiquitous Data Management, UDM 2005, pp. 17-24. IEEE (2005)

38. Molina, A., Bell, R.: Reference models for the computer aided support of simultaneous engineering. International Journal of Computer Integrated Manufacturing 15(3), 193-213 (2002) 